\title{
A note on turbulent spots over a rough bed in wave boundary layers
}

\author{
Carstensen, Stefan; Sumer, B. Mutlu; Fredsøe, Jørgen
}

Published in:

Physics of Fluids

Link to article, DOI:

$10.1063 / 1.4767536$

Publication date:

2012

Document Version

Publisher's PDF, also known as Version of record

Link back to DTU Orbit

Citation (APA):

Carstensen, S., Sumer, B. M., \& Fredsøe, J. (2012). A note on turbulent spots over a rough bed in wave boundary layers. Physics of Fluids, 24, Paper 115104. https://doi.org/10.1063/1.4767536

\section{General rights}

Copyright and moral rights for the publications made accessible in the public portal are retained by the authors and/or other copyright owners and it is a condition of accessing publications that users recognise and abide by the legal requirements associated with these rights.

- Users may download and print one copy of any publication from the public portal for the purpose of private study or research.

- You may not further distribute the material or use it for any profit-making activity or commercial gain

- You may freely distribute the URL identifying the publication in the public portal

If you believe that this document breaches copyright please contact us providing details, and we will remove access to the work immediately and investigate your claim. 


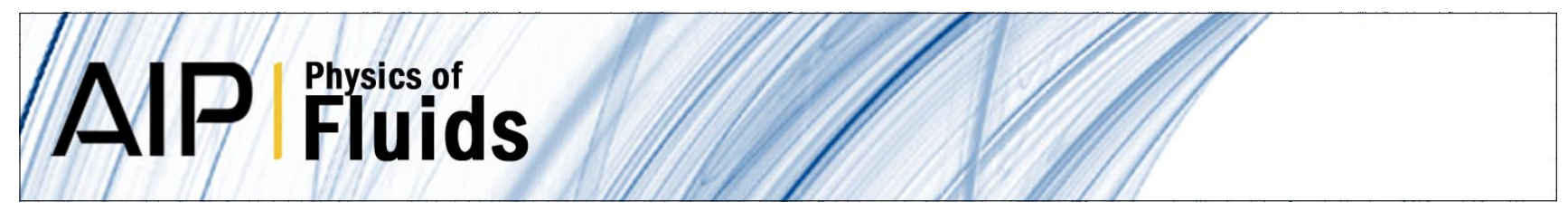

\title{
A note on turbulent spots over a rough bed in wave boundary layers
}

\author{
S. Carstensen, B. M. Sumer, and J. Fredsøe
}

Citation: Phys. Fluids 24, 115104 (2012); doi: 10.1063/1.4767536

View online: http://dx.doi.org/10.1063/1.4767536

View Table of Contents: http://pof.aip.org/resource/1/PHFLE6/v24/i11

Published by the American Institute of Physics.

\section{Related Articles}

Visualization of the structural response of a hypersonic turbulent boundary layer to convex curvature Phys. Fluids 24, 106103 (2012)

Investigations on the local entrainment velocity in a turbulent jet

Phys. Fluids 24, 105110 (2012)

Lagrangian evolution of the invariants of the velocity gradient tensor in a turbulent boundary layer

Phys. Fluids 24, 105104 (2012)

Effects of moderate Reynolds numbers on subsonic round jets with highly disturbed nozzle-exit boundary layers Phys. Fluids 24, 105107 (2012)

Particle transport in a turbulent boundary layer: Non-local closures for particle dispersion tensors accounting for particle-wall interactions

Phys. Fluids 24, 103304 (2012)

\section{Additional information on Phys. Fluids}

Journal Homepage: http://pof.aip.org/

Journal Information: http://pof.aip.org/about/about_the_journal

Top downloads: http://pof.aip.org/features/most_downloaded

Information for Authors: http://pof.aip.org/authors

\section{ADVERTISEMENT}

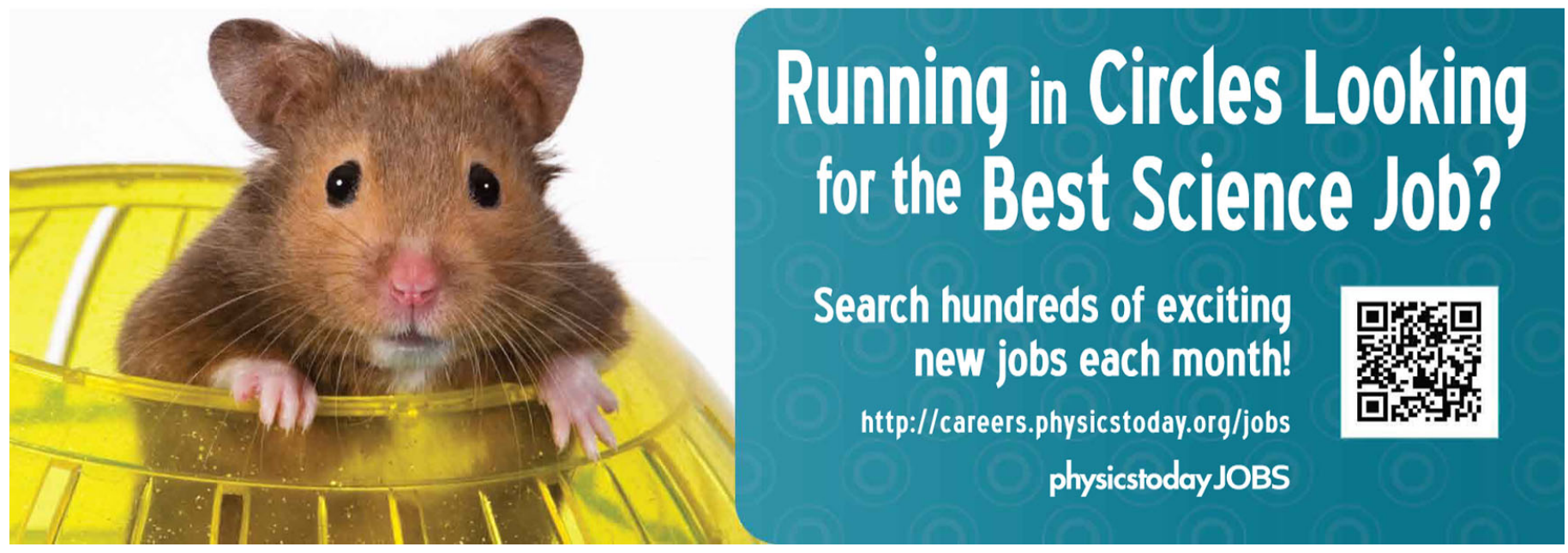




\title{
A note on turbulent spots over a rough bed in wave boundary layers
}

\author{
S. Carstensen, ${ }^{\text {a) }}$ B. M. Sumer, ${ }^{\text {b) }}$ and J. Fredsøe \\ Technical University of Denmark, DTU Mekanik, Section of Coastal, Maritime and \\ Structural Engineering, Building 403, 2800 Kgs. Lyngby, Denmark
}

(Received 3 April 2012; accepted 12 October 2012; published online 27 November 2012)

\begin{abstract}
This study is a continuation of the investigation of turbulent spots in wave boundary layers over a smooth wall reported by Carstensen et al. [J. Fluid Mech. 646, 169-206 (2010)]. The present paper summarises the results of an experimental investigation of turbulent spots in wave boundary layers over a rough wall. Two kinds of experiments were made: flow visualization tests and velocity profile measurements. The experiments show that turbulent spots as observed in the smooth-wall wave boundary layers are present irrespective of wall roughness conditions. As in the smooth-wall case the turbulent spots over the rough wall appear locally in time and space and grow in size as time progresses. ( 2012 American Institute of Physics. [http://dx.doi.org/10.1063/1.4767536]
\end{abstract}

\section{INTRODUCTION}

Turbulent spots are isolated areas close to the wall, in an otherwise laminar boundary-layer flow, where the flow "bursts" with violent oscillations. Turbulent spots were first observed in steady boundary layers over a smooth wall by Emmons. ${ }^{2}$

In two recent studies, turbulent spots were documented in wave boundary layers over a smooth wall: Carstensen, Sumer, and Fredsøe ${ }^{1}$ for oscillatory motion and Sumer et al. ${ }^{3}$ for solitary motion. Carstensen, Sumer, and Fredsøe ${ }^{1}$ revealed the following features of naturally forming turbulent spots. The turbulent spots, cf. Figure 1, form locally in time and space in each half-cycle of the motion for $R e>1.5 \times 10^{5}$. At the critical Reynolds number $\left(R e_{c r}=1.5 \times 10^{5}\right)$ the turbulent spots first appear in the deceleration stage prior to the near-bed flow reversal. With increasing Reynolds number they appear at earlier phases of the half-cycle. These flow features cause single or multiple spikes in the wall shear stress signal and mark the transition to turbulence. The magnitude of these spikes can be as much as a factor of 3 or 4 larger (sometimes even larger) than the maximum wall shear stress associated with the maximum free-stream velocity. For higher Re numbers concurrently occurring turbulent spots may merge and form the fully developed turbulent boundary layer. The lifetime of the turbulent spots or the fully developed turbulent boundary layer comes to an end by the time the flow reverses and the boundary layer progresses into the next half-cycle of the motion. We note that the observations made by Carstensen, Sumer, and Fredsøe ${ }^{1}$ were actually analogous to those made for steady boundary layers (e.g. Gad-el-Hak, Blackwelder, and Riley; ${ }^{4}$ Perry, Lim, and Teh; ${ }^{5}$ Chambers and Thomas; ${ }^{6}$ Browand and Plocher; ${ }^{7}$ Seifert and Wygnanski $;{ }^{8}$ and Matsubara and Alfredsson ${ }^{9}$ ).

Most recently Mazzuoli, Vittori, and Blondeaux ${ }^{10}$ made direct numerical simulations of the oscillatory boundary-layer flow. The results of this study confirmed the experimental findings of Carstensen, Sumer, and Fredsøe. ${ }^{1}$ In the numerical simulations the turbulent spots appeared at about the end of the accelerating phases at the Reynolds numbers investigated $\left(R e=3.0 \times 10^{5}\right.$ and $R e=4.5 \times 10^{5}$ ) and caused spikes in the wall shear stress and the velocity fields.

\footnotetext{
a) Present address: DHI, Agern Alle 5, 2970 Hørsholm, Denmark.

b) Author to whom correspondence should be addressed. Electronic mail: bms@mek.dtu.dk.
} 


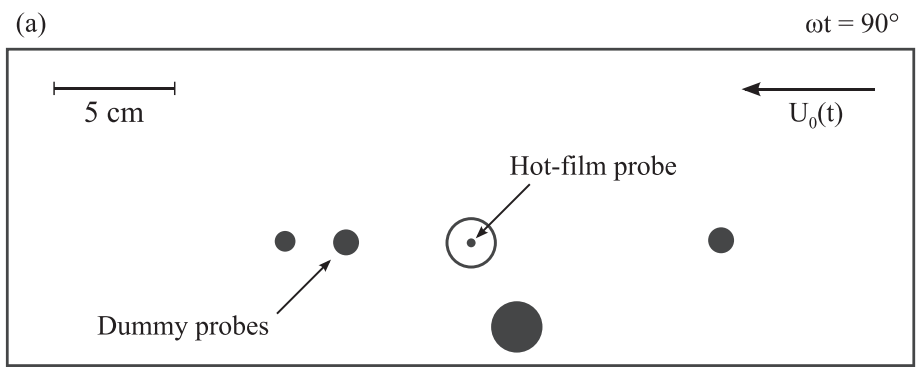

(b) $\omega \mathrm{t}=134^{\circ}$

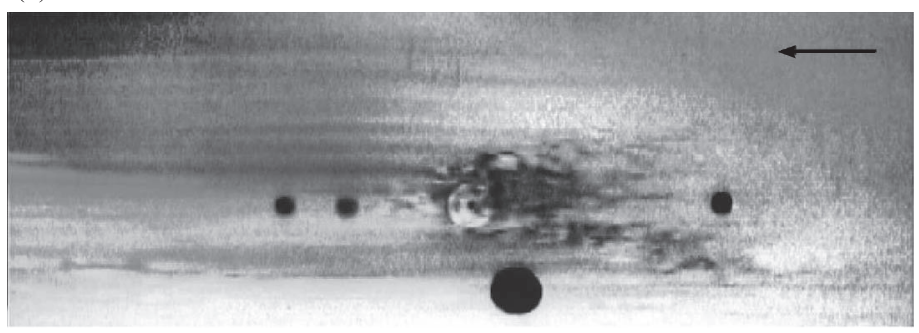

FIG. 1. Video frame illustrating a turbulent spot over a smooth wall $\left(R e=4.5 \times 10^{5}\right)$. Adapted from Carstensen, Sumer, and Fredsøe, ${ }^{1}$ Figure 9 . The four circular black spots are dummy probes mounted flush to the wall.

Previously, direct numerical simulations (see, for example, Akhavan, Kamm, and Shapiro; ${ }^{11}$ Vittori and Verzicco; ${ }^{12}$ and Costamagna, Vittori, and Blondeaux ${ }^{13}$ ) have also successfully been utilised to capture transition to turbulence over hydraulic smooth beds, in the form of spikes in the wall shear stress signal (or in the near wall velocity signal) prior to the near wall flow reversal in oscillatory boundary-layer flows, in line with experimental observations (Hino, Sawamoto, and Takasu; ${ }^{14}$ and Jensen, Sumer, and Fredsøe ${ }^{15}$ ). An extensive review of transition to turbulence in oscillatory boundary-layer flows is given in Carstensen, Sumer, and Fredsøe. ${ }^{1}$

In most practical situations wave boundary layers occur over rough beds (e.g., beds covered with sand or gravel). Turbulence properties in wave boundary layers over rough beds have been the focus in a few studies, e.g., Keiller and Sleath, ${ }^{16}$ Sleath, ${ }^{17}$ Jensen, Sumer, and Fredsøe, ${ }^{15}$ and Fornarelli and Vittori ${ }^{18}$ (see also, e.g., Grass ${ }^{19}$ for a description of the similarity of structural features of turbulent flow over smooth and rough boundaries in steady currents). Yet the laminar-turbulent transition is not fully understood and to the authors' knowledge, no study is yet available investigating turbulent spots over rough boundaries in oscillatory flows. The purpose of this study is to address this question to determine whether turbulent spots occur in wave boundary layers over rough boundaries.

\section{EXPERIMENTAL FACILITY}

The experiments were carried out in a U-shaped oscillatory-flow water tunnel. This tunnel is the same as that described by Jensen, Sumer, and Fredsøe. ${ }^{15}$ The working section was $10 \mathrm{~m}$ long, $0.29 \mathrm{~m}$ high, and $0.39 \mathrm{~m}$ wide. The top and side walls were made of smooth transparent perspex plates. The bottom wall was a fixed sand-grain bed. The oscillatory flow in the tunnel was driven by an electronically controlled pneumatic system. The period of the oscillations was maintained at $9.72 \mathrm{~s}$, the natural period of the oscillating water tunnel.

The fixed sand-grain bed was achieved by gluing sand of fairly uniform size one layer deep on the bottom wall. The roughness height of this wall was measured to be $k=0.25 \mathrm{~cm}$ (Figure 2). This resulted in Nikuradse's equivalent sand-roughness value of $k_{s}=0.50 \mathrm{~cm}$ (see Sec. IV C).

The horizontal velocity component was measured by a Laser-Doppler anemometer (LDA). The LDA system was used in forward-scatter mode and was equipped with a frequency shifter and a frequency tracker.

A hot-film probe was installed in the fixed sand-grain bed to measure the heat-transfer, which is directly related to changes in flow velocities, in the bottom boundary layer. The hot-film probe (which 


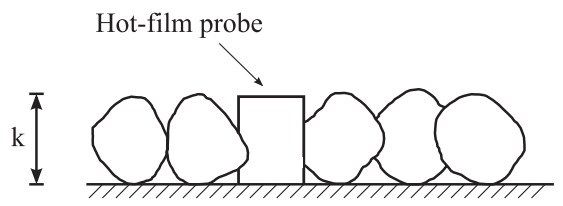

(a)

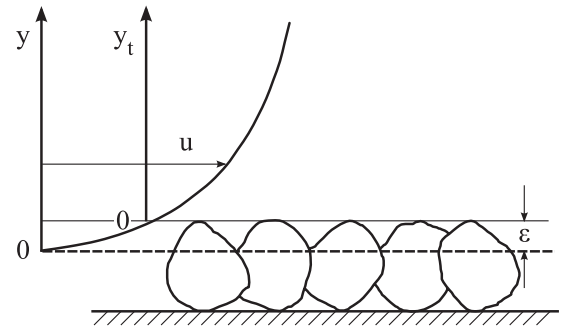

(b)

FIG. 2. Definition sketch.

has approximately the same dimensions as one grain) acted as a roughness element as illustrated in Figure 2(a). The hot-film probe was not used to measure the bed shear stress as the bed was not a smooth boundary, but rather it was used to detect any change in the flow caused by a turbulent spot, as will be discussed in detail later.

The electrical output of the measurement equipment was connected to an appropriate recording system for data storage.

Two kinds of measurements were performed: plan-view flow visualizations and velocity profile measurements. The method used in the flow visualization tests was exactly the same as in Carstensen, Sumer, and Fredsøe. ${ }^{1}$ The flow visualizations were made synchronised with the free-stream velocity and the hot-film measurements. The following procedure was adopted in the tests: (a) Release the dye when the water is at rest; (b) make sure the bottom area where the dye spreads well coincides with the viewing area of the camera; (c) start the video recording and the data sampling shortly before the water is set into motion from rest; (d) continue recording as the amplitude of the oscillatory motion is increased steadily with each half-cycle, Figure 3(a); and (e) continue to do so until the dye is completely dispersed (dispersed so much that the flow visualization becomes practically impossible). The dye used was skimmed milk, coloured with ordinary red food colour, and diluted with water at a ratio of 1:9. Prior to injection the dye had been cooled to a temperature around $5{ }^{\circ} \mathrm{C}$. At this temperature the density of water is close to its maximum so that the dye remains in a thin layer at the bottom. In order to avoid density gradient due to temperature differences, the dye was, after injection, allowed to reach the same temperature as the surrounding water before the test was conducted.

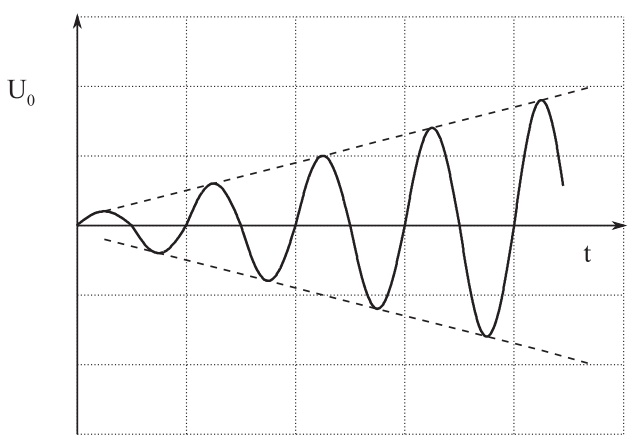

(a)

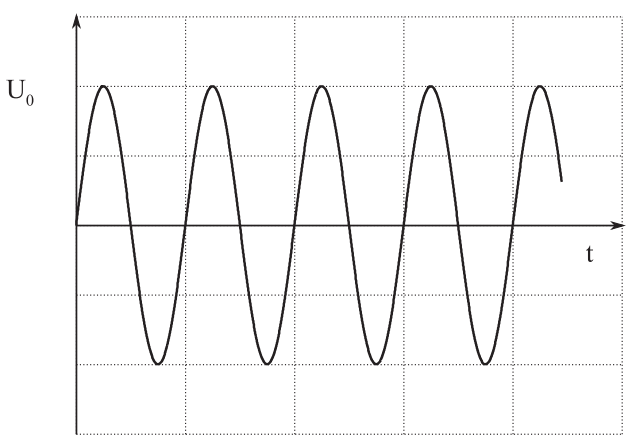

(b)

FIG. 3. (a) Free-stream velocity for flow visualization tests. (b) Free-stream velocity for velocity profile measurements. 
TABLE I. Maximum bed friction velocity determined by: (a) measured velocity profile, (b) Eq. (11) in Kamphuis,${ }^{20}$ and (c) interpolation in Figure 9 in Kamphuis. ${ }^{20}$ The grain Reynolds number $k_{s}^{+}$is also indicated, where $k_{s}=2 k=0.5 \mathrm{~cm}$.

\begin{tabular}{lcccc}
\hline \hline $\begin{array}{l}R e \\
(-)\end{array}$ & $\begin{array}{c}u_{f m} \\
\left(\mathrm{~cm} \mathrm{~s}^{-1}\right)\end{array}$ & $\begin{array}{c}u_{f m} \\
\left(\mathrm{~cm} \mathrm{~s}^{-1}\right)\end{array}$ & $\begin{array}{c}u_{f m} \\
\left(\mathrm{~cm} \mathrm{~s}^{-1}\right)\end{array}$ & $\begin{array}{c}k_{s}^{+}=\frac{k_{s} u_{f m}}{v} \\
(-)\end{array}$ \\
\hline $0.4 \times 10^{5}$ & 1.2 & 1.6 & 1.8 & $60-90$ \\
$0.8 \times 10^{5}$ & 2.3 & 2.2 & 2.4 & $110-120$ \\
$1.1 \times 10^{5}$ & 2.6 & 2.5 & 2.7 & $120-140$ \\
& (a) & (b) & (c) & \\
\hline \hline
\end{tabular}

The velocity measurements were made at several $y_{t}$ locations from the bed, Figure 2(b) (and at the centre of the flume width) with the purpose of determining the mean and turbulence characteristics of the motion as a function of the distance from the bed, as well as to determine the friction velocity $u_{f}$.

\section{TEST CONDITIONS}

The free-stream oscillatory flow is defined by

$$
U_{0}=U_{0 m} \sin (\omega t)
$$

where $U_{0 m}$ is the amplitude of the free-stream velocity, $\omega$ is the angular frequency

$$
\omega=\frac{2 \pi}{T}
$$

and $T$ is the period of the oscillatory motion. The amplitude of the motion is calculated from

$$
a=\frac{U_{0 m} T}{2 \pi} .
$$

The Reynolds number is defined by

$$
R e=\frac{a U_{0 m}}{v},
$$

where $v$ is the kinematic viscosity $\left(0.01 \mathrm{~cm}^{2} \mathrm{~s}^{-1}\right)$. The water temperature was $22{ }^{\circ} \mathrm{C}$.

In each flow visualization test the amplitude of the free-stream velocity was increased steadily with each progressing half-cycle similar to Carstensen, Sumer, and Fredsøe, ${ }^{1}$ Figure 3(a). Ten flow visualization tests with varying rates of increase of the amplitude of the free-stream velocity were performed. The number of half-cycles visualized, before the dye had dispersed completely, was on average 6 half-cycles. The total number of visualized half-cycles were therefore in the order of 60 and the Reynolds number for the visualized half-cycles was in the range of $R e<1 \times 10^{5}$.

Separate velocity profile measurements were made in tests where the amplitude of the oscillating flow was maintained constant, Figure 3(b). These tests were performed at three Reynolds numbers: $R e=0.4 \times 10^{5}, R e=0.8 \times 10^{5}$, and $R e=1.1 \times 10^{5}$. The horizontal velocity was measured over 40 wave periods for each Reynolds number and $y_{t}$ location, while the amplitude of the free-stream velocity was kept constant. Table I gives the test conditions for the velocity measurements. The way in which the friction velocity has been determined is described in Sec. IV C.

\section{RESULTS AND DISCUSSION}

\section{A. Turbulent spots over sand-grain bed}

In the range $5 \times 10^{4}<R e<1 \times 10^{5}$ arrowhead-shaped flow features have been observed over the sand-grain bed in oscillatory flow. Figure 4 shows a sequence of video frames and accompanying sketches of two such arrowhead-shaped flow features observed. The supplementary material (Movie $1^{21}$ ), from which the video frames exhibited in Figure 4 were taken, shows the time development of the observed features in real time. The features show similar characteristics as the turbulent spots 

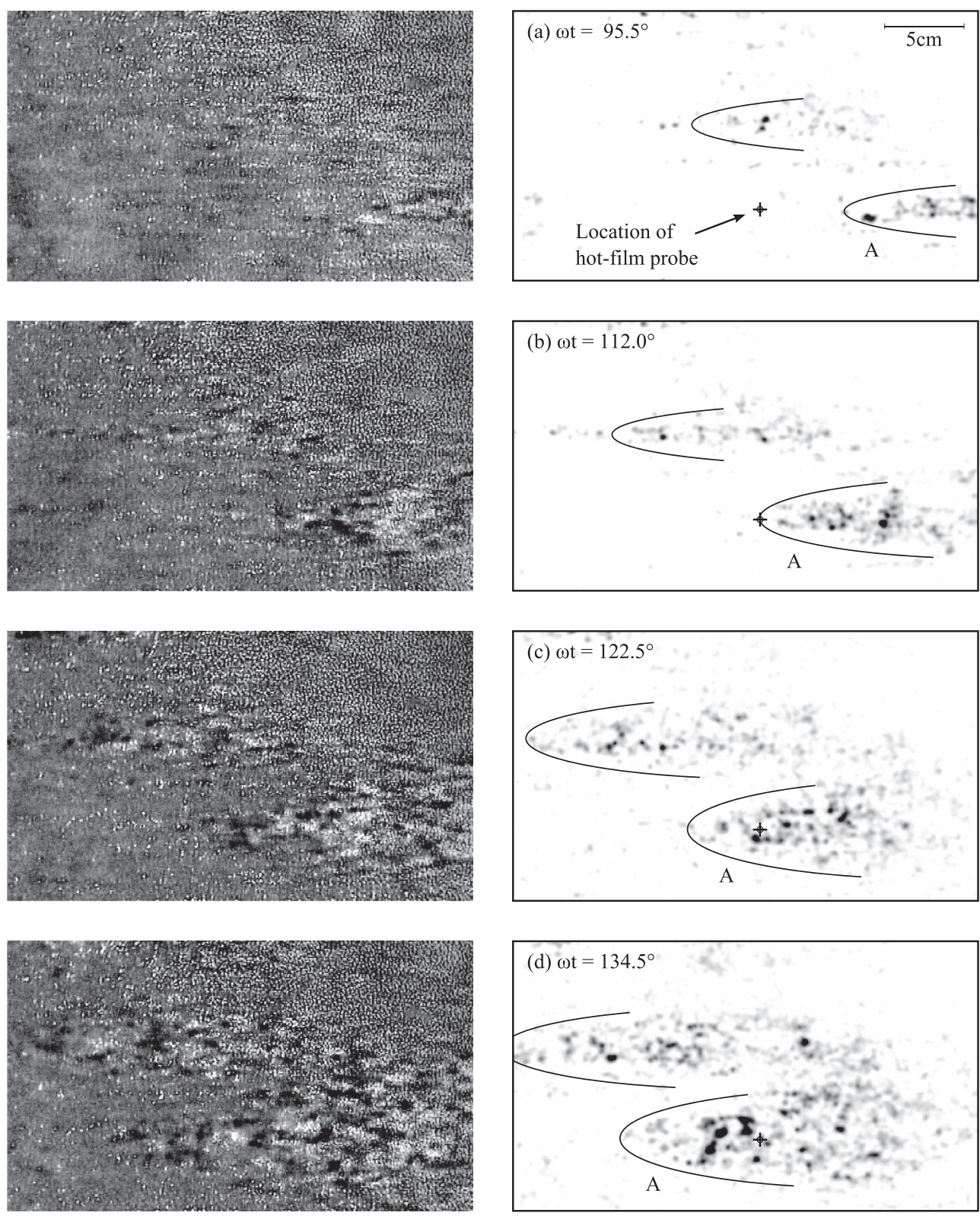

FIG. 4. Turbulent spots forming over the sand-grain bed, video frames, and accompanying sketches: (a) $\omega t=95.5^{\circ}$, (b) $\omega t$ $=112.0^{\circ}$, (c) $\omega t=122.5^{\circ}$, and (d) $\omega t=134.5^{\circ} . R e=7.8 \times 10^{4}$. Flow direction from right to left. The plus sign ( + ) marks the location of the hot-film probe. The supplementary material, Movie $1,{ }^{21}$ shows the time development of the turbulent spots in real time.

observed in the smooth-wall oscillatory boundary layer flow (Carstensen, Sumer, and Fredsøe ${ }^{1}$ ), cf. Figure 1.

One of the turbulent spots, spot A in Figure 4, passes over the hot-film probe during the phase interval $112^{\circ}<\omega t<130^{\circ}$, Figures 4(b) -4 (d). The hot-film probe signal for this half-cycle (and thus the response of the hot-film probe to the passage of the spot) is shown in Figure 5. The figure shows that spike A coincides with the passage of the turbulent spot (spot A in Figure 4). It is notable that the length scales of the turbulent spots and the turbulence inside them well exceed the size of the individual roughness elements and therefore the length scale of small-scale turbulence generated by the vortex shedding behind individual roughness elements. 


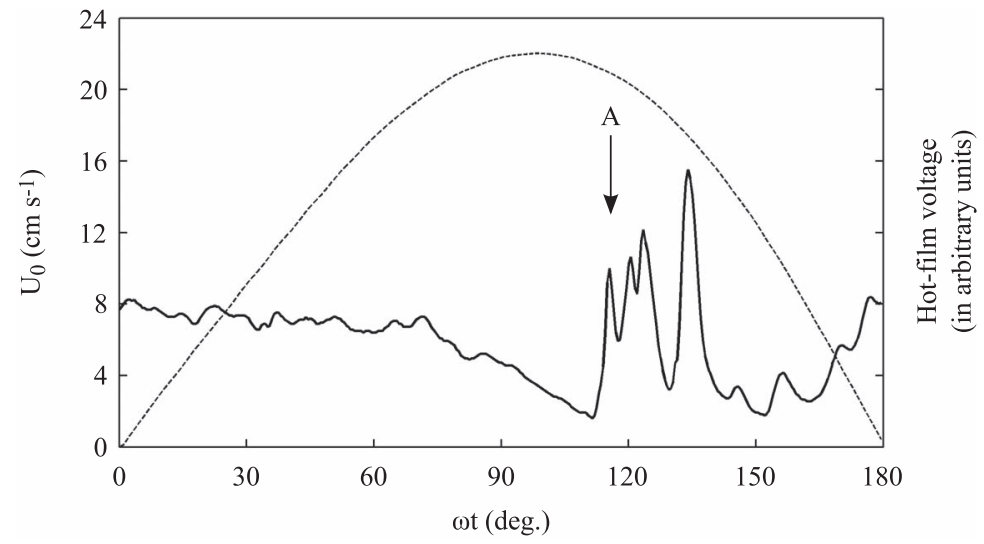

FIG. 5. The signature of the turbulent spot, spot A, Figure 4, in the time-series of the hot-film probe. The location of the hot-film probe is shown in Figure 4. Dashed line: free-stream velocity, $U_{0}$. Solid line: hot-film voltage in arbitrary units.

Figure 6 shows the phase of the birth of the turbulent spots versus the Reynolds number for the sand-grain bed case. The figure also includes the smooth-bed data of Carstensen, Sumer, and Fredsøe ${ }^{1}$ for comparison. $R e_{c r}=1.5 \times 10^{5}$, the critical Reynolds number for laminar-to-turbulence transition in the smooth-bed case, is also indicated in the figure. The following conclusions can be drawn from Figure 6. First, the Reynolds number at which the turbulent spots first emerge in the case of the sandgrain bed is reduced considerably, namely, $R e_{c r} \approx 5 \times 10^{4}$, a value much smaller than the smooth-bed $R e_{c r}=1.5 \times 10^{5}$. This is consistent with the steady-boundary layer knowledge (e.g., Dryden, ${ }^{22}$ see Schlichting and Gersten, ${ }^{23}$ Figure 15.38, p. 472). Second, the trend where the phase of birth decreases with $R e$ appears to be much the same as in the smooth-bed case. Jensen, Sumer, and Fredsøe ${ }^{15}$ note that turbulence first occurs just prior to the bed shear stress reversal because the adverse pressure gradient becomes relatively large and the velocity of near-bed fluid particles becomes relatively small at this phase value so that a very favourable environment forms for the initiation of turbulence. With increasing $R e$ transition to turbulence spreads towards smaller and smaller values of phase.

\section{B. Properties of sand-grain bed turbulent spot}

The growth of turbulent spots is reported in literature (e.g., Schubauer and Klebanoff ${ }^{24}$ ) as the speed of the leading and trailing edge, the angle of the leading sides, and the spreading angle

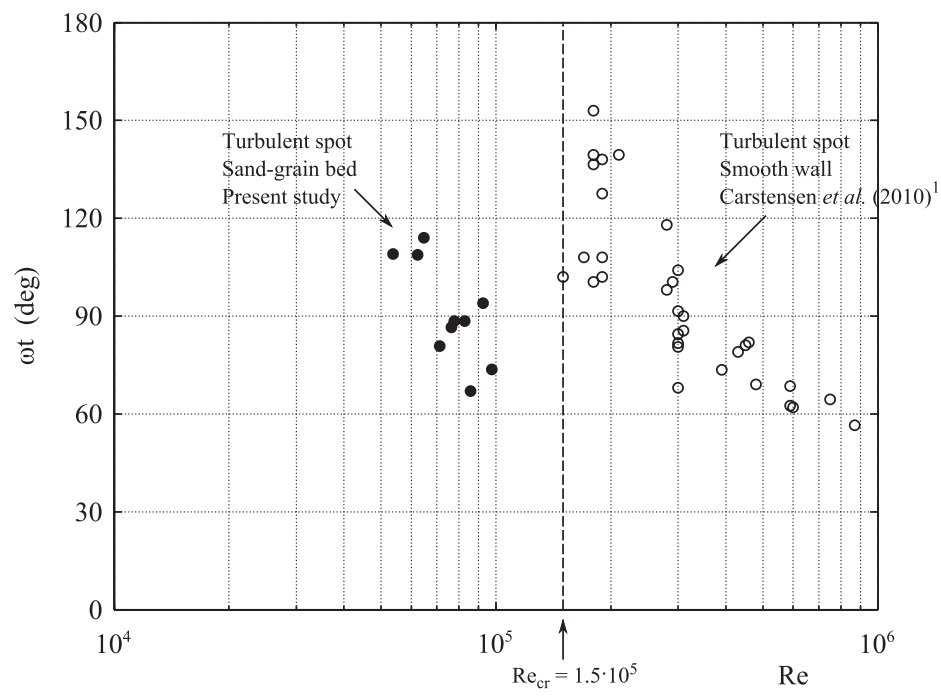

FIG. 6. Birth of turbulent spots. Filled circles: Present study, sand-grain bed; Empty circles: Carstensen, Sumer, and Fredsøe, ${ }^{1}$ smooth wall. Roughness elements reduce the critical Reynolds number for the formation of turbulent spots. 


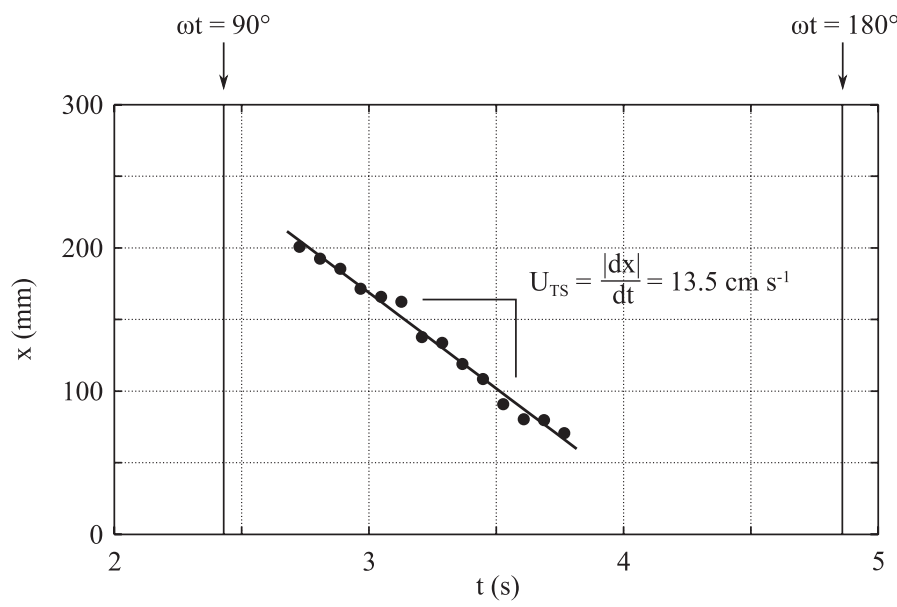

FIG. 7. Position of the leading-edge of the turbulent spot, spot A, shown in Figure 4 versus time.

(the half angle of the wedge left by the turbulent region). Figure 11(a) defines these parameters. Of these, the leading-edge speed and the angle of the leading sides of the turbulent spot shown in Figure 4 (sand-grain bed) have been determined over the phase range $\omega t=95^{\circ}-140^{\circ}$. The former has been determined from the leading-edge position versus time, plotted in Figure 7. The leadingedge speed of the turbulent spot shown in Figure 4 has been found to be $U_{T S}=13.5 \mathrm{~cm} \mathrm{~s}^{-1}$. The leading-edge speed of turbulent spots in steady, smooth-wall boundary layers is often estimated to be approximately 0.9 times the free-stream velocity $\left(0.88 U_{0}\right.$ according to Schubauer and Klebanoff $\left.{ }^{24}\right)$, but the specific value depends on the details of the experiment and the criterion used for determining the leading-edge speed. In oscillatory flow, the free-stream velocity varies over time. However, it is possible to define an average phase-resolved free-stream velocity

$$
\overline{U_{0}(\omega t)}=\frac{1}{\omega t_{2}-\omega t_{1}} \int_{\omega t_{1}}^{\omega t_{2}} U_{0}(\omega t) d(\omega t) .
$$

The average phase-resolved free-stream velocity for the phase range $95^{\circ}<\omega t<140^{\circ}$ (Figure 4) has been measured to be $20.1 \mathrm{~cm} \mathrm{~s}^{-1}$. This means that the leading-edge speed of the turbulent spot forming over the sand-grain bed is 0.67 times the phase-resolved free-stream velocity $\left(U_{T S} / \overline{U_{0}(\omega t)}\right.$ $=0.67$ ), a value that is somewhat smaller than the value 0.9 found in steady, smooth wall flows. In Sec. IV D, the cause of the discrepancy will be further explored. The angle of the leading sides of the turbulent spot shown in Figure 4 has been found to be $12.2^{\circ}$, a value that is presumably smaller than the $15.3^{\circ}$ reported by, e.g., Schubauer and Klebanoff ${ }^{24}$ for steady flow over a flat plate.

In Sec. IV C, the velocity profile measurements are analyzed to support the findings of the flow visualizations. In this case, instantaneous velocity time series are employed to keep the relationship with the flow visualizations as close as possible. The primary reason for the velocity profile measurements is, however, to provide an estimate of the bed shear stress. Following common practice, the bed shear stress in the wave boundary layer is given as the maximum bed shear stress. In this case, ensemble-averaged velocity profiles are employed.

\section{Velocity profile measurements}

Figure 8 shows the instantaneous near bed velocity at the three Reynolds numbers: (a) $R e$ $=0.4 \times 10^{5}$, (b) $R e=0.8 \times 10^{5}$, and (c) $R e=1.1 \times 10^{5}$. For each Reynolds number a number of half-cycles have been depicted to show the variability in the velocity signal.

Starting at $R e=0.4 \times 10^{5}$, fluctuations in the near bed velocity are visible throughout the half-cycle. However in the deceleration stage, just prior to the near bed flow reversal, fluctuations in and the actual value of the near bed velocity are occasionally large. In addition the large near bed velocities are seen to cause a delayed near bed flow reversal. The spikes in the near bed velocity 

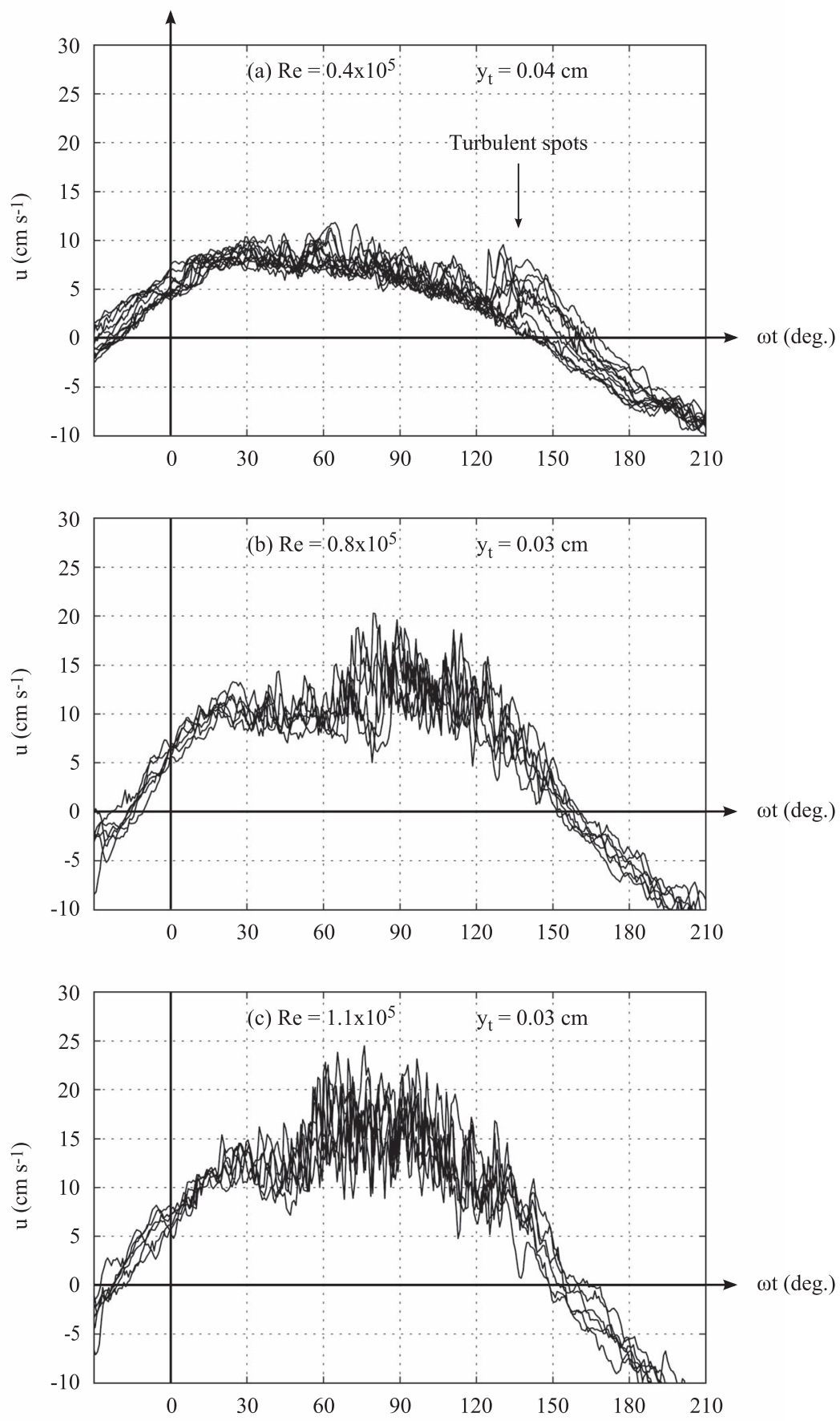

FIG. 8. Instantaneous horizontal near bed velocities for the three Reynolds numbers: (a) $R e=0.4 \times 10^{5}$, (b) $R e=0.8 \times 10^{5}$, and (c) $\operatorname{Re}=1.1 \times 10^{5}$.

show similar behaviour as the spike in the bed shear stress in smooth-wall oscillatory flow prior to the flow reversal, Carstensen, Sumer, and Fredsøe. ${ }^{1}$ The present flow visualizations have shown turbulent spots to form over the sand-grain bed and be related to increased near bed velocities. From this it can be deduced that the spikes seen in the near bed velocity, Figure 8(a), over the sand-grain bed are related to the passage of turbulent spots. With increased Re turbulence spreads to earlier phases in agreement with our previous research (Carstensen, Sumer, and Fredsøe; ${ }^{1}$ Jensen, Sumer, and Fredsøe $\mathrm{e}^{15}$ ) while the near bed flow reversal in general is delayed. 
The change in the level of turbulence in the velocity signal can be interpreted as a transition from a perturbed laminar flow $\left(\right.$ Coleman ${ }^{25}$ ) to a rough turbulent flow. Furthermore, the general delay of the near bed flow reversal indicates that turbulent spots have merged to form the fully developed turbulent boundary layer.

Coleman ${ }^{25}$ studied steady laminar flow over a surface with roughness elements. For this case the streamlines in the immediate vicinity of the roughness elements will not be straight and parallel. However, this effect ceases to exist further away from the wall so that at some level the laminar velocity profile equation becomes an appropriate expression for the velocity profile, provided that what Coleman ${ }^{25}$ terms the virtual origin can be adequately defined.

Following the concept of perturbed laminar flow the oscillatory velocity profile at $R e=0.4 \times$ $10^{5}\left(\omega t<120^{\circ}\right)$ is expected to be described by (see, e.g. Batchelor ${ }^{26}$ )

$$
u(y, t)=U_{0 m} \sin (\omega t)-U_{0 m} \exp \left(-\frac{3 \pi}{4} \frac{y}{\delta}\right) \sin \left(\omega t-\frac{3 \pi}{4} \frac{y}{\delta}\right),
$$

where $y=y_{t}+\epsilon$, Figure 2(b), and $\delta=\delta_{t}+\epsilon$ is the boundary layer thickness, which, in the smooth wall case, reads

$$
\delta=\frac{3 \pi}{4} \delta_{1}=\frac{3 \pi}{4} \sqrt{\frac{2 v}{\omega}}
$$

The boundary layer thickness from the top of the grains $\delta_{t}$ may be found from the measured vertical velocity profile leaving only $\epsilon$ to be determined. A best-fit of (6) to the measured velocity profile gives $\epsilon=0.15 k$, in which $\epsilon$ is the distance between the theoretical bed and the top of the grains, Figure 9 (the top of the grains $=$ the average level of the top of the individual grains in the case of natural sand). Figure 9 shows the measured velocity profile at $R e=0.4 \times 10^{5}\left(\omega t=90^{\circ}\right)$, the smallest Reynolds number tested, together with Eq. (6). The maximum friction velocity can be found using Eq. (6). The maximum friction velocity is found to be $u_{f m}=1.2 \mathrm{~cm} \mathrm{~s}^{-1}$ (Table I).

At $R e=1.1 \times 10^{5}$, the highest Reynolds number tested, the flow is rough turbulent for $\omega t>60^{\circ}$ according to Figure 8(c). Figure 10 shows the velocity profile for $\omega t=80^{\circ}$ and for $\omega t=90^{\circ}$ for this test. In a turbulent oscillatory flow the phase lead of the friction velocity to the free-stream velocity is expected to be approximately $10^{\circ}$ (Jensen, Sumer, and Fredsøe ${ }^{15}$ ). This is confirmed by the near

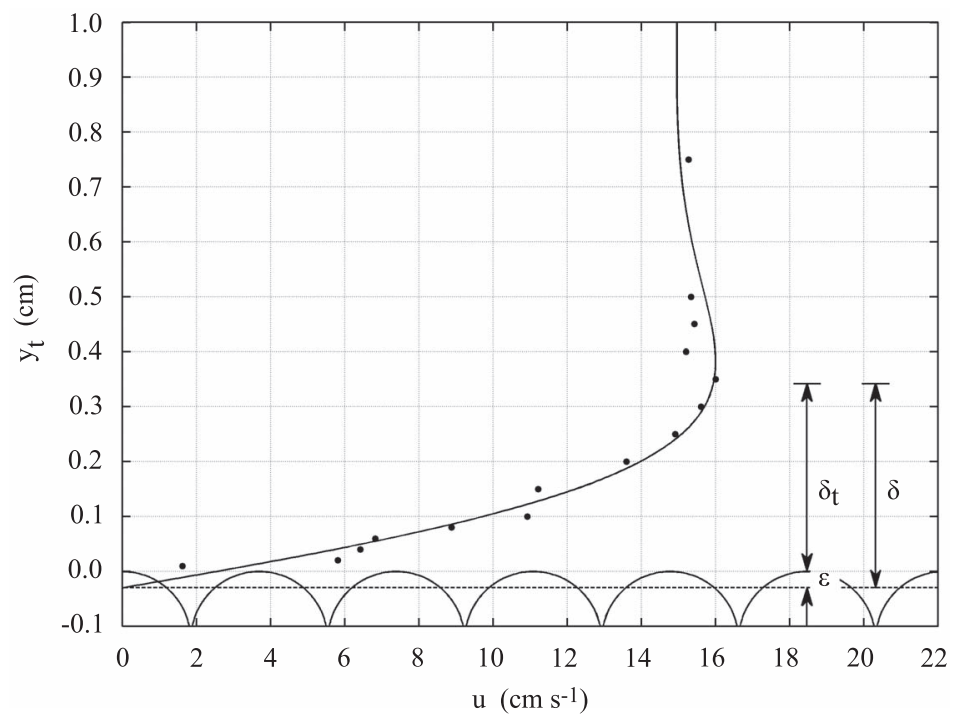

FIG. 9. Vertical velocity profile at $R e=0.4 \times 10^{5}, \omega t=90^{\circ}$. Points: measurements, ensemble-averaged values. Solid line: best-fit of Eq. (6) to the measured velocity profile. $\delta=\delta_{t}+\epsilon$ is the boundary layer thickness, in which $\delta_{t}$ is the boundary layer thickness from the top of the sand grains. 


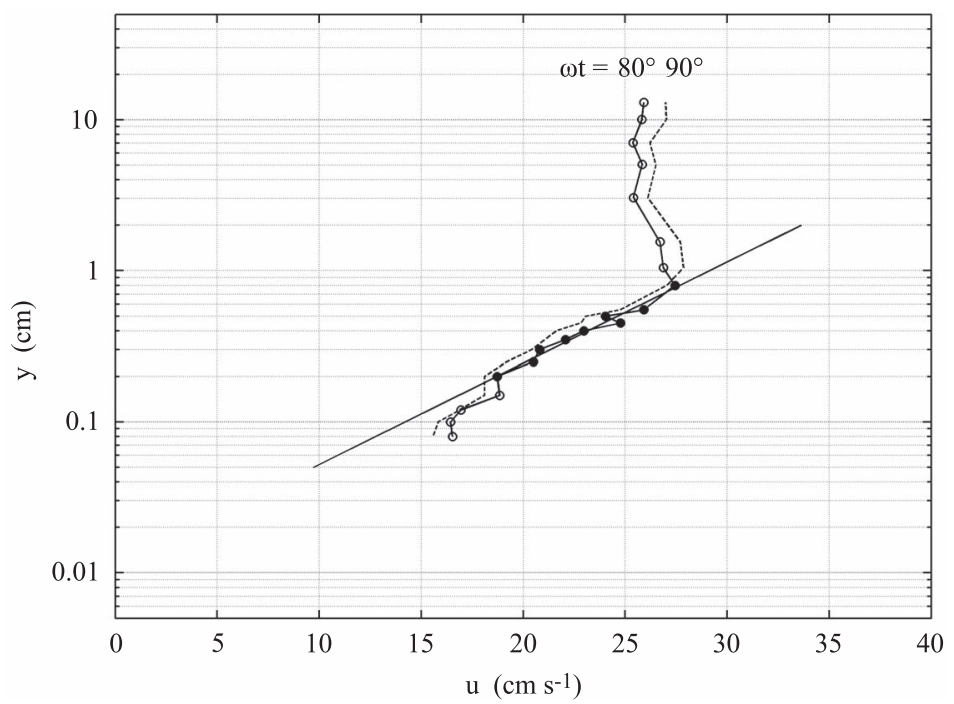

FIG. 10. Vertical velocity profile at $R e=1.1 \times 10^{5}$. Empty and filled circles: measurements, ensemble-averaged values at $\omega t=80^{\circ}$. Dashed line: measurements, ensemble-averaged values at $\omega t=90^{\circ}$. Solid line: the logarithmic law fitted to the logarithmic layer (filled circles). The straight line has a slope equal to $2.5 u_{f m}$ since the bed shear stress attains its maximum at $\omega t=80^{\circ}$.

bed flow velocities, Figure 8(c). The maximum friction velocity may therefore be obtained from the $\log$-fit procedure on the velocity profile at $\omega t=80^{\circ}$. The log-fit procedure gives $u_{f m}=2.6 \mathrm{~cm} \mathrm{~s}^{-1}$ and Nikuradse's equivalent roughness as $k_{s}=2 k$. This value is in the range of Nikuradse's equivalent roughness reported in literature for various wall roughnesses $\left(\right.$ Bayazit $\left.^{27}\right)$. A similar exercise has been performed for $R e=0.8 \times 10^{5}$, the intermediate Reynolds number tested. The result is given in Table I. Also included in Table I is the predicted friction velocity by (b) Eq. (11) in Kamphuis ${ }^{20}$ and from (c) interpolation in Figure 9 in Kamphuis. ${ }^{20}$ The table shows that there is a reasonable good agreement between the different methods for determining the maximum friction velocity. However, at $R e=0.4 \times 10^{5}$ there is a somewhat larger discrepancy, which is expected as methods (b) and (c) are not entirely valid for the perturbed laminar flow.

Finally, comparing Figures 9 and 10 it is seen that the boundary layer increases from $O(0.4 \mathrm{~cm})$ in the perturbed laminar regime to $O(1 \mathrm{~cm})$ in the rough turbulent regime.

\section{Discussion}

The flow visualization and the velocity profile measurements have shown that turbulent spots as observed in wave boundary layer over a smooth wall are also present for oscillatory flow over the sand-grain bed. The grain Reynolds number for the oscillatory flow over the sand-grain bed has been determined and has been found to be $k_{s}^{+}>O(60)$ when turbulent spots first emerge. A grain Reynolds number larger than 70 is usually synonymous with a fully rough boundary.

The above description and discussion lead to the conclusion that turbulent spots, as observed in the smooth-wall oscillatory boundary layer, are present irrespective of wall roughness conditions at least up to the order of the present roughness conditions. The effect of the roughness is to lower the critical Reynolds number for the formation of turbulent spots (Figure 6). Turbulent spots form when $R e>1.5 \times 10^{5}$ in the case of a smooth-wall boundary, while for the present sand-grain bed turbulent spots form as early as $R e=4 \times 10^{4}$. Other aspects of the formation of turbulent spots in the rough-wall case appear similar to the smooth-wall case.

The growth of turbulent spots is sketched in Figure 11(a). In steady flow over a flat plate, it has been found that the speed of the leading and trailing edge of a turbulent spot scales with the free-stream velocity. In oscillatory flow, the free-stream velocity varies over time. The situation is illustrated in Figures 11(b) and 11(c). Figure 11(c) shows a bed shear stress time series with two 
(a)

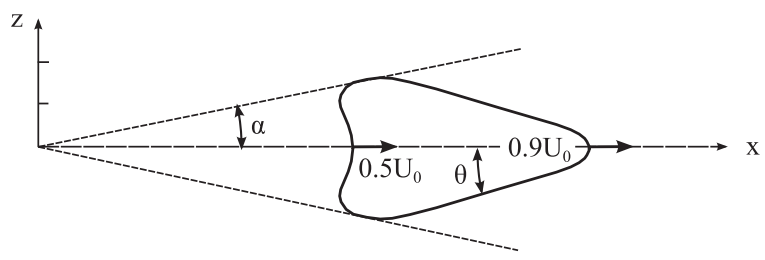

(b)

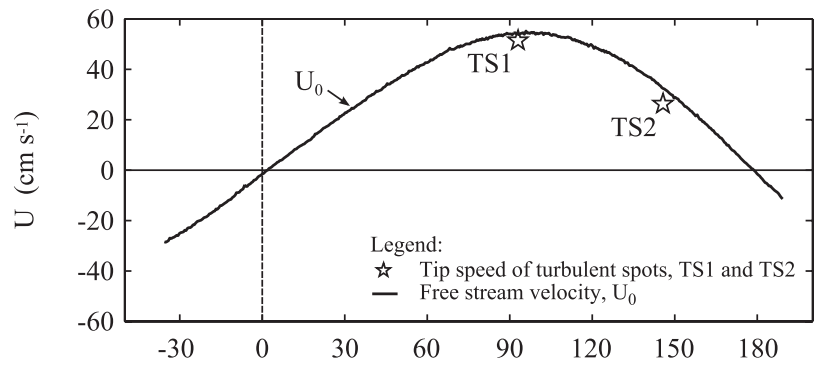

(c)

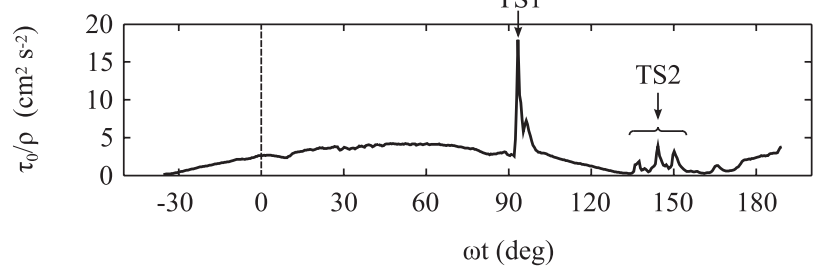

FIG. 11. Growth of turbulent spots. (a) Sketch of plan view of observed turbulent spot, modified from Schubauer and Klebanoff, ${ }^{24}$ (b) phase-resolved free-stream velocity, (c) bed shear stress from Carstensen, Sumer, and Fredsøe, ${ }^{1}$ Figure 14. TS1: Turbulent Spot 1; and TS2: Turbulent Spot 2 (Figure 1). The leading-edge speed of both TS1 and TS2 appears to scale with $U_{0}(\omega t)$ in which $U_{0}(\omega t)$ is the phase-resolved free-stream velocity. $\theta$ is the angle of the leading sides and $\alpha$ is the spreading angle.

successive turbulent spots forming over a smooth wall. The turbulent spot designated TS2 is the one shown in Figure 1(b). Figure 11(b) shows the free-stream velocity for this half-cycle. Also included in the figure is the speed of the leading-edge of the two turbulent spots (star symbol). The leadingedge speed of both TS1 and TS2 appears to scale with $U_{0}(\omega t)$ in which $U_{0}(\omega t)$ is the phase-resolved free-stream velocity. The speed of the leading edge is found to be $0.95 \overline{U_{0}(\omega t)}$ and $0.79 \overline{U_{0}(\omega t)}$ for TS1 and TS2, respectively. Table II, rows 2 and 3, gives the growth of the two turbulent spots in tabulated form. Also included in the table is the growth of: a third turbulent spot in oscillatory flow

TABLE II. Growth of turbulent spots. The leading-edge speed of turbulent spot is given in terms of the ratio $R_{U}=U_{T S} / U_{0}(\omega t)$ in which $U_{T S}$ is the leading-edge speed of turbulent spot and $U_{0}(\omega t)$ is the phase-resolved free-stream velocity. $\theta$ and $\alpha$ are defined in Figure 11(a). Additional data sources: (TS1) Carstensen, Sumer, and Fredsøe, ${ }^{1}$ Figures 13(a) and 13(b); (TS3) Carstensen, Sumer, and Fredsøe, ${ }^{1}$ Figure 12(a); (TSA) Schubauer and Klebanoff, ${ }^{24}$ see also Schlichting and Gersten ${ }^{23}(2000$, p. 421).

\begin{tabular}{|c|c|c|c|c|c|c|c|c|}
\hline $\begin{array}{l}\text { Sample no. } \\
(-)\end{array}$ & $\begin{array}{c}U_{0 m} \\
\left(\mathrm{~cm} \mathrm{~s}^{-1}\right)\end{array}$ & $\begin{array}{c}\omega t \\
(\operatorname{deg})\end{array}$ & $\begin{array}{c}\overline{U_{0}(\omega t)} \\
\left(\mathrm{cm} \mathrm{s}^{-1}\right)\end{array}$ & $\begin{array}{c}U_{T S} \\
\left(\mathrm{~cm} \mathrm{~s}^{-1}\right)\end{array}$ & $R_{U}=\frac{U_{T S}}{\bar{U}_{0}(\omega t)}$ & $\begin{array}{c}\theta \\
(\operatorname{deg})\end{array}$ & $\begin{array}{c}\alpha \\
(\operatorname{deg})\end{array}$ & $\begin{array}{l}\text { Description } \\
\quad(-)\end{array}$ \\
\hline \multicolumn{9}{|c|}{ Sand-grain bed, oscillatory flow (present) } \\
\hline TSR & 22.0 & $95-140$ & 20.1 & 13.5 & 0.67 & 12.2 & $\ldots$ & Figure 4, spot A \\
\hline \multicolumn{9}{|c|}{ Smooth bed, oscillatory flow (present) } \\
\hline TS1 & 54.2 & $89-97$ & 54.2 & 51.3 & 0.95 & $\ldots$ & 10 & \multirow{3}{*}{ Figure 1} \\
\hline $\mathrm{TS} 2$ & 54.2 & $134-155$ & 33.3 & 26.4 & 0.79 & 15.7 & 11.5 & \\
\hline TS3 & 44.0 & $122-143$ & 37.1 & 33.1 & 0.89 & 13.9 & 10.9 & \\
\hline \multicolumn{9}{|c|}{ Steady flow over a flat plate (Schubauer and Klebanoff ${ }^{24}$ ) } \\
\hline TSA & $U_{\infty}=10^{3}$ & $x=70 \mathrm{~cm}$ & $\ldots$ & $\ldots$ & 0.88 & 15.3 & 11.3 & \\
\hline
\end{tabular}


over a smooth wall (row 4); the turbulent spot forming over the sand-grain bed shown in Figure 4 (row 1); and (row 5) turbulent spots in steady flow over a flat plate according to Schubauer and Klebanoff. ${ }^{24}$ Although limited to a few samples, the data in Table II exhibit the following features: (1) When scaled with the phase-resolved free-stream velocity, the leading-edge speed of smooth-bed turbulent spots appears to be in good agreement with that reported by Schubauer and Klebanoff ${ }^{24}$ for steady boundary-layer flow over a flat plate (cf. Rows 2-5 in Table II). (2) As already mentioned, the leading-edge speed of sand-grain bed turbulent spot, 0.67, is distinctly smaller than that of smooth-bed turbulent spots, 0.79-0.95. This may be attributed to the retarding effect of the sandgrain roughness of the bed. No study is yet available investigating important properties of turbulent spots including the leading-edge speed, the trailing-edge speed, the angle of the leading sides, and the spreading angle in oscillatory flow with both smooth and rough boundaries. The limited analysis presented herein has been undertaken on the suggestion of one of the reviewers and it appears that the aspect of the problem would be worth exploring further.

\section{CONCLUSION}

Turbulent spots have been observed and analyzed over a rough boundary in oscillatory flow. This, together with the recent observations of turbulent spots in oscillatory flow over a smooth-wall boundary, leads to the conclusion that turbulent spots are present irrespective of wall roughness conditions. As in the smooth-wall case the turbulent spots over the rough wall are associated with large near bed velocities. They appear locally in time and space and grow in size as time progresses.

\section{ACKNOWLEDGMENTS}

This study has been partially funded by (i) the Danish Research Council for Technology and Production Science (FTP) under the research program Exploitation and Protection of Coastal Zones (EPCOAST) and (ii) the Danish Council for Strategic Research through the research program Seabed and Wind Farm Interaction.

${ }^{1}$ S. Carstensen, B. M. Sumer, and J. Fredsøe, "Coherent structures in wave boundary layers. Part 1. Oscillatory motion,” J. Fluid Mech. 646, 169-206 (2010).

${ }^{2}$ H. W. Emmons, "The Laminar-Turbulent transition in a boundary layer - Part I," J. Aeronaut. Sci. 18, 490-498 (1951).

${ }^{3}$ B. M. Sumer, P. M. Jensen, L. B. Sørensen, J. Fredsøe, P. L.-F. Liu, and S. Carstensen, "Coherent structures in wave boundary layers. Part 2. Solitary motion,” J. Fluid Mech. 646, 207-231 (2010).

${ }^{4}$ M. Gad-el-Hak, R. Blackwelder, and J. Riley, "On the growth of turbulent regions in laminar boundary layers," J. Fluid Mech. 110, 73-95 (1981).

${ }^{5}$ A. Perry, T. Lim, and E. Teh, “A visual study of turbulent spots,” J. Fluid Mech. 104, 387-405 (1981).

${ }^{6}$ F. Chambers and A. Thomas, "Turbulent spots, wave packets and growth," Phys. Fluids 26, 1160-1162 (1983).

${ }^{7}$ F. Browand and D. A. Plocher, "Image processing for sediment transport," in Proceedings of the 21st IAHR Congress, Melbourne, Australia, 1985, pp. 19-23.

${ }^{8}$ A. Seifert and I. J. Wygnanski, "On turbulent spots in a laminar boundary layer subjected to a self-similar adverse pressure gradient," J. Fluid Mech. 296, 185-209 (1995).

${ }^{9}$ M. Matsubara and P. H. Alfredsson, "Disturbance growth in boundary layers subjected to free-stream turbulence," J. Fluid Mech. 430, 149-168 (2001).

${ }^{10}$ M. Mazzuoli, G. Vittori, and P. Blondeaux, “Turbulent spots in oscillatory boundary layers," J. Fluid Mech. 685, 365-376 (2011).

${ }^{11}$ R. Akhavan, R. D. Kamm, and A. H. Shapiro, "An investigation of transition to turbulence in bounded oscillatory Stokes flows. Part 2. Numerical simulations” J. Fluid Mech. 225, 423-444 (1991).

${ }^{12}$ G. Vittori and R. Verzicco, "Direct simulation of transition in an oscillatory boundary layer," J. Fluid Mech. 371, 207-232 (1998).

${ }^{13}$ P. Costamagna, G. Vittori, and P. Blondeaux, "Coherent structures in oscillatory boundary layers," J. Fluid Mech. 474, 1-33 (2003).

${ }^{14}$ M. Hino, M. Sawamoto, and S. Takasu, "Experiments on transition to turbulence in an oscillatory pipe flow," J. Fluid Mech. 75, 193-207 (1976).

${ }^{15}$ B. L. Jensen, B. M. Sumer, and J. Fredsøe, "Turbulent oscillatory boundary layers at high Reynolds numbers," J. Fluid Mech. 206, 265-297 (1989).

${ }^{16}$ D. C. Keiller and J. F. A. Sleath, "Velocity measurements close to a rough plate oscillating in its own plane," J. Fluid Mech. 73, 673-691 (1976).

${ }^{17}$ J. F. A. Sleath, “Turbulent oscillatory flow over rough beds,” J. Fluid Mech. 182, 369-409 (1987). 
${ }^{18}$ F. Fornarelli and G. Vittori, “Oscillatory boundary layer close to a rough wall,” Eur. J. Mech. B/Fluids 28, 283-295 (2009).

${ }^{19}$ A. J. Grass, "Structural feastures of turbulent flow over smooth and rough boundaries," J. Fluid Mech. 50, 233-255 (1971).

${ }^{20}$ J. W. Kamphuis, "Friction factor under oscilatory waves," J. Wtrwy., Harb. and Coast. Engrg. Div. 101, 135-144 (1975).

${ }^{21}$ See supplementary material at http://dx.doi.org/10.1063/1.4767536 for Movie 1.

${ }^{22} \mathrm{H}$. L. Dryden, "Review of published data on the effect of roughness on transition from laminar to turbulent flow" J. Aeronaut. Sci. 20, 477-482 (1953).

${ }^{23} \mathrm{H}$. Schlichting and K. Gersten, Boundary Layer Theory (Springer, 2000).

${ }^{24}$ G. B. Schubauer and P. S. Klebanoff, "Contributions on the mechanics of boundary layer transition," Technical Note NACA-TN-3489 (National Advisory Committee for Aeronautics), 1955.

${ }^{25}$ N. L. Coleman, "The laminar flow velocity profile over close-packed spherical roughness elements," Houille Blanche $\mathbf{1}$, 13-22 (1982).

${ }^{26}$ G. K. Batchelor, An Introduction to Fluid Dynamics (Cambridge University Press, 1967).

${ }^{27}$ M. Bayazit, "Flow structure and sediment transport mechanics in steep channels," in Proceedings of Euromech 156 on Mechanics of Sediment Transport, Istanbul, Turkey, 1983, pp. 197-206. 